\title{
Validation of Satellite-Based PERSIANN Rainfall Estimates Using Surface-Based APHRODITE Data over Iran
}

\author{
Javad Bodagh Jamli, ${ }^{1,2}$ \\ ${ }^{1}$ The Environmental Engineering Faculty, the University of Environment, Karaj, Iran \\ ${ }^{2}$ The Atmospheric Science and Meteorological Research Center (ASMERC), Tehran, Iran
}

Email address:

jbjamali@gmail.com

\section{To cite this article:}

Javad Bodagh Jamli. Validation of Satellite-Based PERSIANN Rainfall Estimates Using Surface-Based APHRODITE Data over Iran. Earth Sciences. Vol. 4, No. 5, 2015, pp. 150-160. doi: 10.11648/j.earth.20150405.11

\begin{abstract}
Surface-based precipitation measurements with high accuracy on different spatial-temporal scales have a crucial importance in different land-use planning sectors, especially in arid and semi-arid regions, such as Iran. Because the density of spatial distribution of rain-gauges is not uniform throughout the country, satellite sensor technology is considered useful for precipitation monitoring over the study area. In this study, PERSIANN satellite-based rainfall data were validated through comparison with the APHRODITE surface-based precipitation data. The validation was carried out for annual and seasonal precipitation, as well as an inter-annual comparison. Our analysis was based on a visual comparison and a statistical approach, including linear regression and spatial correlation between APHRODITE and PERSIANN datasets for each $0.25^{\circ} \times 0.25^{\circ}$ grid cell in the entire country, in the Caspian Sea region, and in the Zagros Mountains, indicating spatial correlation coefficients of 0.62, 0.62, 0.47, respectively. Both APHRODITE data and PERSIANN data showed that spatial distribution of mean annual and seasonal precipitation over Iran has two main patterns: along the Caspian Sea and along the Zagros Mountain chain. In general, PERSIANN underestimates high rainfall rates by $5.5 \mathrm{~mm} /$ day in winter but overestimates the low rainfalls in annual and seasonal scales by $0.9 \mathrm{~mm} /$ day in summer.
\end{abstract}

Keywords: Precipitation Validation, Satellite Data, PERSIANN, APHRODITE, Iran, Gridded Data

\section{Introduction}

Accurate measurements of precipitation on a variety of space and time scales are important, not only to weather forecasters and climate scientists but also to a wide range of decision makers, including hydrologists, agriculturalists, emergency managers, and industrialists ${ }^{1}$.

Rainfall is a highly dynamic process, constantly changing in form and intensity over a given area. Traditionally, rainfall is measured by use of rain a gauge, an instrument that accurately measures the actual amount of rain that falls into it ${ }^{2}$.

However, even in well-populated regions with sophisticated infrastructure, simple point-based measurements by the use of rain-gauges may not be sufficient for characterizing the spatial patterns of precipitations. Further, the spatial distribution of gauge-observing networks shows that they are typically concentrated in locations with proper infrastructural facilities. (e.g., at lower elevations, near principal natural resources, along transportation corridors, and near electricity and communications networks), and mere presence of these features does not guarantee adequate sampling of the spatial distribution of rainfall structures ${ }^{3}$.

During the past few decades, satellite-sensor technology has facilitated the development of innovative approaches for making precipitation related observations on a global scale. Clearly, satellite-based technologies have the potential to provide improved estimates for large portions of the world where gauge observations are limited ${ }^{4}$.

Appropriate use of satellite products requires establishment of their accuracy and consideration of the expected error, especially in developing countries such as Iran, which lacks a sufficient rain-gauge network.

Javanmard et al. (2010) ${ }^{5}$ evaluated satellite rainfall estimates of the Tropical Rain Measurement Mission (TRMM) level 3 output (3B42) (TRMM 3B42) over Iran $\left(20^{\circ}-45^{\circ} \mathrm{N}, 40^{\circ}-65^{\circ}\right.$ E) by comparison with high-resolution gridded precipitation datasets $\left(0.25^{\circ} \times 0.25^{\circ}\right.$ latitude/longitude $)$ 
based on rain gauges (Iran Synoptic gauges Version 0902 [IS0902]). They found that TRMM 3B42 had underestimated mean annual precipitation for the entire country, the Caspian Sea region, and the Zagros Mountains, by approximately $0.17,0.39$, and $0.15 \mathrm{~mm} /$ day, respectively, compared with IS0902 data, and the mean annual rainfall spatial correlation coefficients were 0.77 (entire country), 0.57 (Caspian Sea region), and 0.75 (Zagros Mountains). The mean annual precipitation temporal correlation coefficient for IS0902 and TRMM 3B42 was 0.8 in the area along the Zagros Mountains and $\sim 0.6$ in the Caspian Sea and desert regions.

The present study shows the validation of the Precipitation Estimation from Remotely Sensed Information Using Artificial Neural Networks (PERSIANN) satellite-based algorithm rainfall data over Iran through comparison with the highly resolved observational gridded precipitation data created by the Asian Precipitation Highly Resolved Observational Data Integration towards Evaluation of Water Resources (APHRODITE) project in Japan.

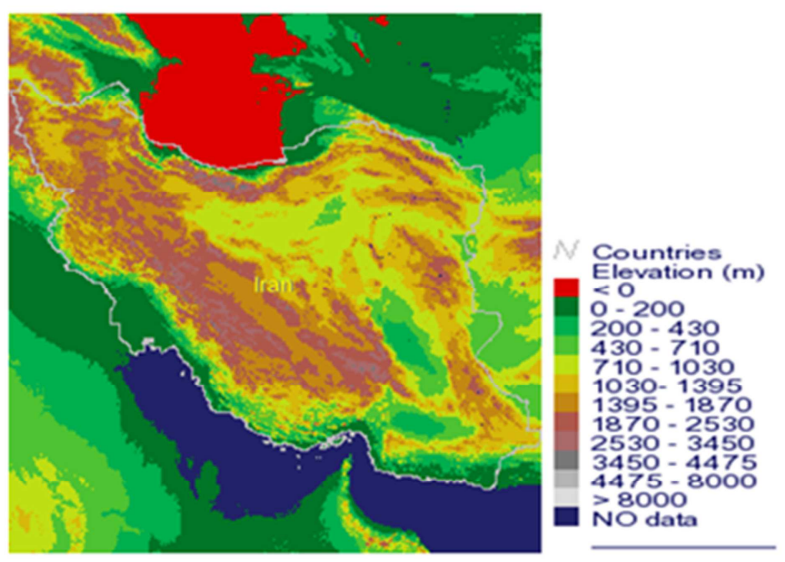

\section{Study Area}

Iran is a semi-arid and wide country, with an area of $1,648,000 \mathrm{~km}^{2}$. The lowest and highest elevations are $\sim-28 \mathrm{~m}$ (Caspian Sea) and 5671m (Damavand Peak), respectively, and the mean annual precipitation is $\sim 250 \mathrm{~mm}$. Vegetation cover in most parts of the country (especially over the central, southern, and eastern parts) is very sparse. Iran is located in the southwest of Asia and borders the Gulf of Oman, the Persian Gulf (in the south), and the Caspian Sea(in the north), with a geographical position of $25^{\circ}-40^{\circ} \mathrm{N}$ and $44^{\circ}-64^{\circ} \mathrm{E}$. The topography of the country features two main mountain chains, the Alborz Mountains, from northwest toward northeast of the country, and the Zagros Mountains which bisect the country from northwest to southeast. The central region of the country consists of several closed water basins that are collectively referred to as the central plateau. The eastern part of the plateau is covered by two salt deserts, the Dasht-e Kavir (Great Salt Desert) and the Dasht-e Lut (Emptiness Desert) (Figure 1).

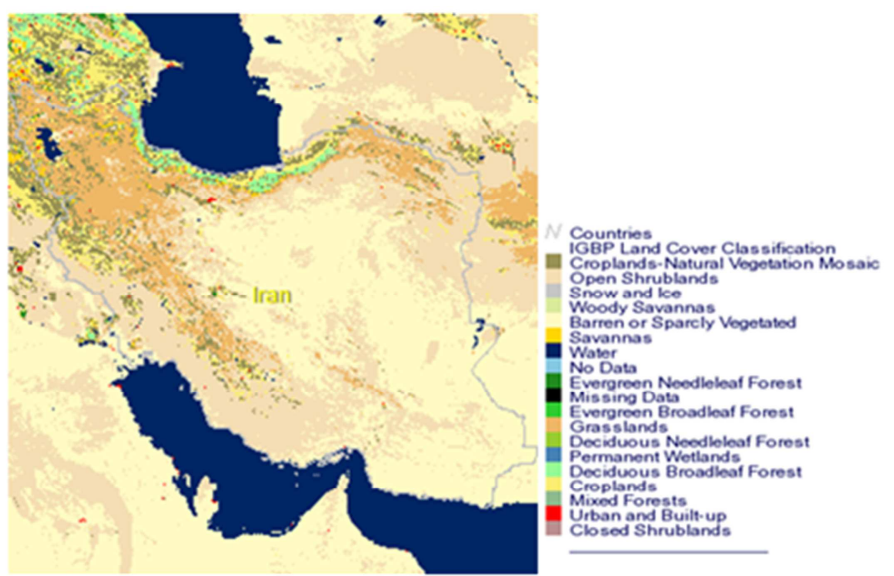

Figure 1. Elevation map (left) and land cover (right) of Iran (Adapted from http://hydis.eng.uci.edu/cgi-bin/).

In winter, the climate of the country is affected by the Siberian Anticyclone, along with a dynamic low-pressure system that originates from the Mediterranean Sea and sometimes traverses the country. In summer, because of the formation of heat lows that lead to anticyclone genesis and a lack of wave cyclones over the Mediterranean region, most parts of Iran do not receive any precipitation, and the mean temperature significantly increases. However, during summer, the northwest of the country (Azarbayjan region), as well as the coastal areas of the Caspian Sea, may receive some light precipitation. Furthermore, monsoon precipitation sometimes influences the southeast of the country in summer.

In autumn, the transitional cyclones frequently traverse the country, and in winter, they gradually become dominant over the most parts of the country, particularly the northwestern, northern, and western regions, but they can also affect southern and eastern regions. The Zagros Mountain chain, from northwest to southeast, is a wide orographic obstacle that could cause the westerly cyclones to deposit more precipitation over the western regions during the winter.

Seasonal distribution of precipitation over most parts of the country indicates that a maximum amount of annual precipitation usually occurs in winter, whereas the provinces around the Caspian Sea (Guilan and Mazandaran) and northwest of Iran (Azarbayjan region) normally receive the maximum precipitation in autumn and spring, respectively ${ }^{6}$.

\section{Materials and Methods}

The PERSIANN algorithm is an adaptive, multi-platform precipitation estimation system that uses $\mathrm{ANN}^{1}$ technology to merge high-quality, sparsely sampled data from NASA, ${ }^{2}$ NOAA, ${ }^{3}$ and DMSP ${ }^{4}$ low-altitude polar-orbital satellites (TRMM ${ }^{5}$, DMSP F-13, F-14 and F-15 and NOAA-15, 16,and -17) with continuously sampled data from geosynchronous satellites $\left(\mathrm{GOES}^{6}\right)^{7-12}$. The precipitation

\footnotetext{
1Artificial Neural Network

2National Aeronautics and Space Administration

3National Oceanic and Atmospheric Administration

4Defense Meteorological Satellite Program

5Tropical Rainfall Measuring Mission

6Geostationary Operational Environmental Satellite
} 
product generated from PERSIANN covers the $50^{\circ} \mathrm{S}-50^{\circ} \mathrm{N}$ domain at $0.25^{\circ}$ spatial resolution and hourly temporal resolution. The algorithm first extracts and classifies local texture features from the long-wave infrared image of geostationary satellites to a number of texture patterns, and then it correlates those classified cloud-texture patterns with the surface rainfall rates ${ }^{13}$. In this study, three-hourly observation of PERSIANN data from 00:00 UTC to 21:00 UTC during 2001 to 2007 over Iran has been used. (Data source: http://chrs.web.uci.edu/persiann/data.html.)

\section{Gridded Rain Gauge-Based Precipitation Data} (APHRO_V1003R1)

Considerable efforts have been made in the development of gridded precipitation datasets based on satellite data or satellite-based merged analyses ${ }^{14-15}$.

There has been an increasing demand for accurate, highresolution, rain gauge-based precipitation products over land for the validation of simulation products of numerical models and satellite-based, high-resolution precipitation products ${ }^{16}$. That is, indirect precipitation estimates must be verified or calibrated by direct observations, specifically rain-gauge measurements $17-18,15$. To date, the assembly of daily precipitation data, quality control (QC), and grid analyses has not progressed to the same degree as for monthly datasets, except over the North American domain. Even in the widely used merged products, ${ }^{19-20}$ input rain gauges are limited to the Global Telecommunication System (GTS) network ( $\sim 6000$ stations over the entire globe). Over Asia, despite highly populated regions and a great necessity for environmental monitoring and prediction, significant differences in estimates among datasets have been reported 21. For example, orographic precipitation along the Himalayas was not well represented by the estimates of the Global Precipitation Climatology Project One-Degree Daily (GPCP1DD) ${ }^{22}$ and other merged products that only contain GTS-based rain-gauge data. Thus, one of the most important current tasks in monitoring and predicting the Asian hydrological environment is to assemble historical daily observation data and develop reliable datasets for contribution to many international scientific purposes 15 . Hence, Yatagai et al. (2005) ${ }^{21}$ initiated the Asian Precipitation-Highly Resolved Observational Data Integration Towards Evaluation of Water Resources (APHRODITE) project to develop state-of-the-art daily precipitation datasets on high-resolution grids covering the whole of Asia and created a daily gridded precipitation dataset for 1961-2004 by collecting rain-gauge observation data through the APHRODITE project.

The number of valid stations were between 5000 and 12,000 , representing 2.3 to 4.5 times the data available through the GTS network, which were used for most daily grid precipitation products.

They released APHRO_V0902 datasets for monsoon Asia, Russia, and the Middle East (on $0.5^{\circ} \times 0.5^{\circ}$ and $0.25^{\circ} \times 0.25^{\circ}$ grids) on the website http://www.chikyu.ac.jp/precip/.The daily gridded precipitation of the APHRODITE project (APHRO_V0902) is the long-term (1961 onward) continental-scale daily product that contains a dense network of daily rain-gauge data for Asia, including the Himalayas and mountainous areas of the Middle East. The algorithm and input data of APHRO_V0902 have been presented by Yatagai et al. (2009) ${ }^{15}$.

In the APHRODITE project, daily precipitation data from meteorological or hydrological organizations in each country were individually collected. Yatagai et al. (2009) ${ }^{15}$ used daily precipitation data from154 World Meteorological Organization (WMO) stations and 183 non-WMO stations of the Islamic Republic of Iran Meteorological Organization (IRIMO) from the website (http://www.irimet.net) over Iran. The data coverage period differed among stations, with the longest period from the 1960 s to the present. In their analysis, they used data from stations with at least 5 years of data to compute the monthly climatology. They also used world climatology data (World Clim) ${ }^{23}$ in the interpolation algorithm.

The steps of the algorithm for deriving the gridded APHRODITE precipitation data are as follows ${ }^{21}$ :

1. Define monthly precipitation climatology from daily and monthly observations at each station.

2. Compute the ratio of step (1) to the WORLDCLIM.

3. Interpolate step (2) onto a $0.05^{\circ}$ grid by use of the new weighted-mean method based on Shepard (1968) ${ }^{24}$.

4. Define daily precipitation climatology by Fourier interpolation with the first six harmonics by use of the daily climatology,

The V0902 daily precipitation analysis was conducted as follows:

5. Compute the ratio of the daily observation to the daily climatology from step (4) for the target day.

6. Interpolate step (5) into a $0.05^{\circ}$ grid by use of the same method used in step (3).

7. Re-grid $0.05^{\circ}$ data from step (6) to $0.25^{\circ}$ and $0.5^{\circ}$ products by use of the area-weighted mean.

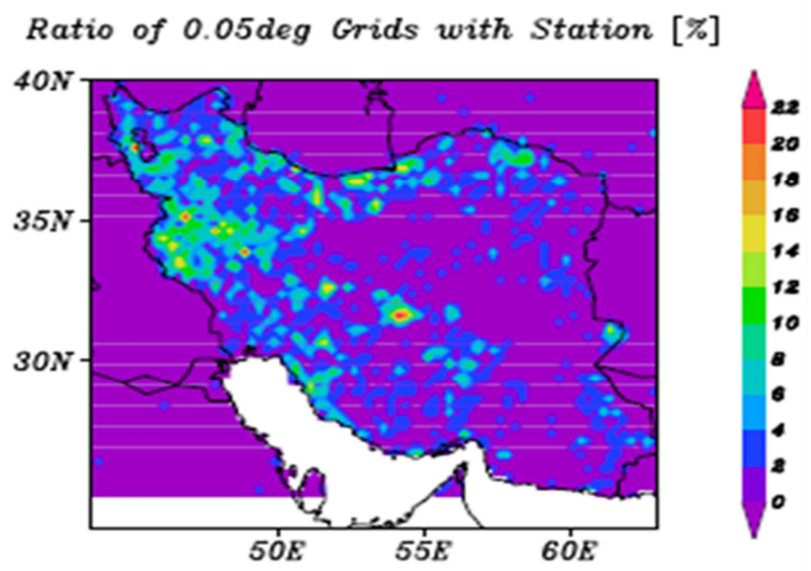

Figure 2. Spatial distribution of gridded rain-gauge data in the APHRODITE project.

Yatagai et al. (2009) ${ }^{15}$ improved their methods for QC and analysis improved the methods, following which they released the APHRO_V1003R1 product, which is used as 
reference data in this research, including more rain-gauge data compared with previous versions (APHRO_V0902 precipitation data) through 1951-2007.The gridded fields of daily precipitation in this product were defined by interpolating rain-gauge observations obtained from meteorological and hydrological stations throughout the regions, as shown in Figure 2.

\section{Validation and Results}

\subsection{Mean Annual Precipitation}

Figure 3 shows mean annual precipitation in grid boxes with spatial resolution of $0.25^{\circ} \times 0.25^{\circ}$ during a period of 2001-2007 over the study area. As can be observed, PERSIANN underestimates high rainfall values along the Caspian Sea and in the Zagros Mountains by $2.7 \mathrm{~mm} /$ day and $2.4 \mathrm{~mm} /$ day, respectively, and overestimates low rainfall values along the central region of country into the southeast of country, where the density of rain-gauge station distribution is low, by $0.3 \mathrm{~mm} /$ day.

PERSIANN underestimates the areal average of annual precipitation as shown in Figure 4.The difference between APHRODITE and PERSIANN data decreases from 2005 to 2007, reaching zero in 2007. The annual rainfall maps from PERSIANN satellite-based data and APHRODITE as reference data from 2001 to 2007 show a maximum difference of $3 \mathrm{~mm} /$ day over the Caspian Sea region between the two data sources during 2001 to 2004. This difference decreases to less than $2.7,2.4$, and $1.5 \mathrm{~mm}$ /day in 2005, 2006, and 2007, respectively. These results indicate the improvement of the PERSIANN performance in recent years because of the increasing number of training parameters of the artificial neural network by use of polar-orbit satellite data in the PERSIANN algorithm.
Mean Annual Precipitation-PERSIANN

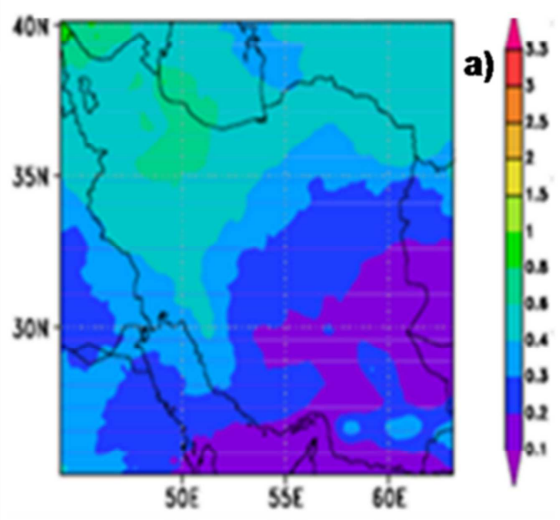

Mean Annual Precipitation-APHRO.

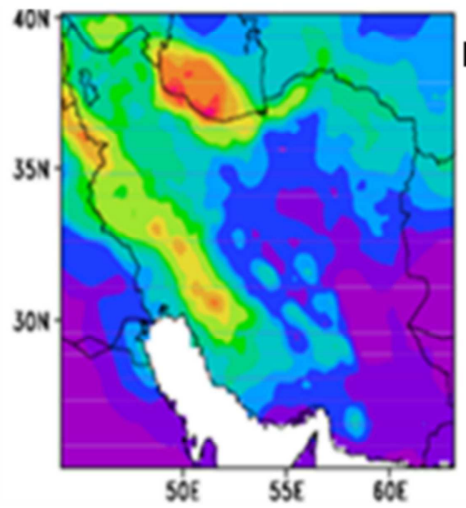

Difference of Mean Annual Precip.

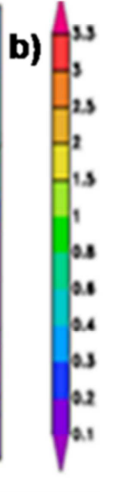

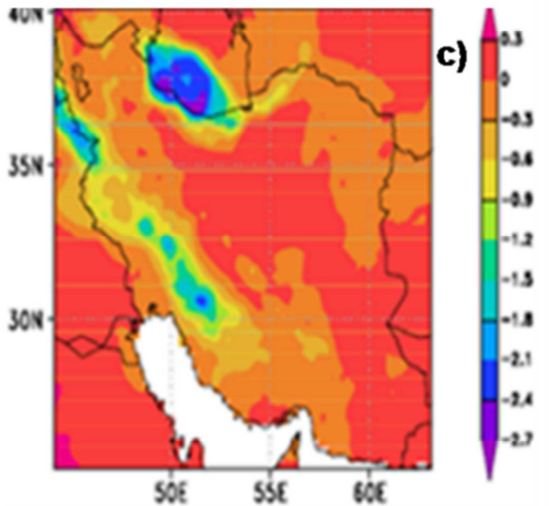

Figure 3. Comparison of mean annual precipitation in APHRODITE and PERSIANN for the time period 2001-2007. (a) PERSIANN (mm/day), (b) APHRODITE (mm/day), (c) difference in mean annual precipitation between APHRODITE and PERSIANN (mm/day).

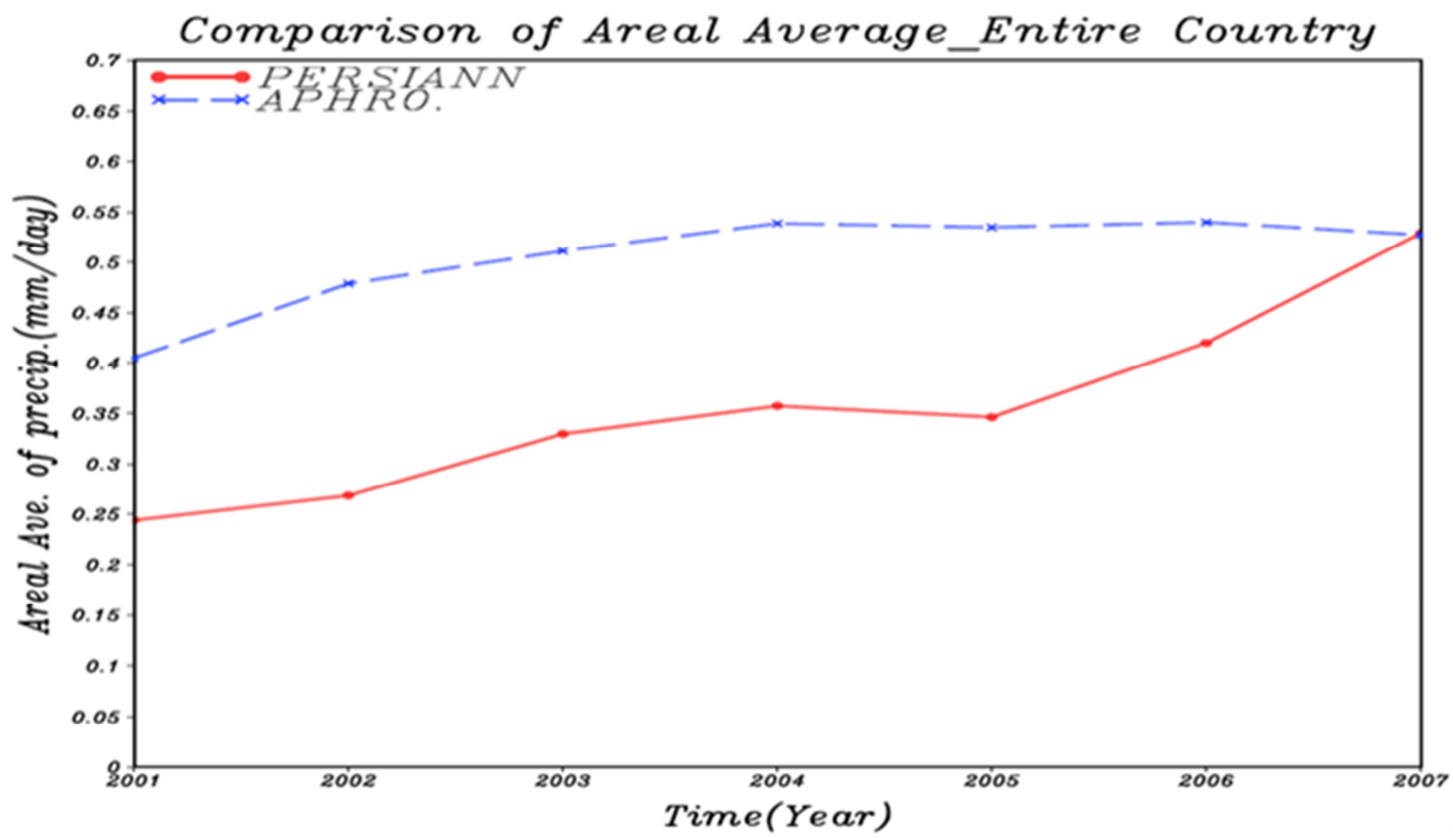

Figure 4. Comparison of annual average areal precipitation by APHRODITE (blue dashed line) and PERSIANN (red solid line) over Iran from 2001 to 2007. 
Figure 6 shows the scatter plots between annual rainfall values of APHRODITE and PERSIANN during 2001-2007 for three regions: the entire country $\left(25^{\circ}-40^{\circ} \mathrm{N}, 44^{\circ}-63^{\circ} \mathrm{E}\right)$ (Region 1), the Caspian Sea $\left(35^{\circ}-40^{\circ} \mathrm{N}, 48^{\circ}-56^{\circ} \mathrm{E}\right)$ (Region $2)$, and the Zagros Mountains $\left(28^{\circ}-37^{\circ} \mathrm{N}, 46^{\circ}-55^{\circ} \mathrm{E}\right)$ (Region 3). Statistical parameters derived by the use of a linear-regression method and the spatial correlation coefficients (SCCs) between mean annual rainfall in APHRODITE and PERSIANN are given in Table 1. SCCs for the entire country, the Zagros Mountains, and the Caspian Sea, are 0.62, 0.62, 0.47, respectively. Javanmard et al.
(2010) ${ }^{5}$ found the SCC values between satellite-based (TRMM3B42) and gauge-based (IS0902) annual rainfall datasets over the three above-mentioned regions to be 0.77 , 0.57 , and 0.75 respectively.

The correlation coefficients show the higher ability of PERSIANN to detect mean annual rainfall in the Caspian Sea region and its lower ability in the Zagros Mountains compared withTRMM3B42 estimations. The number of samples shown in Table 1 refers to the number of grid cells or data pairs used to calculate SCCs.

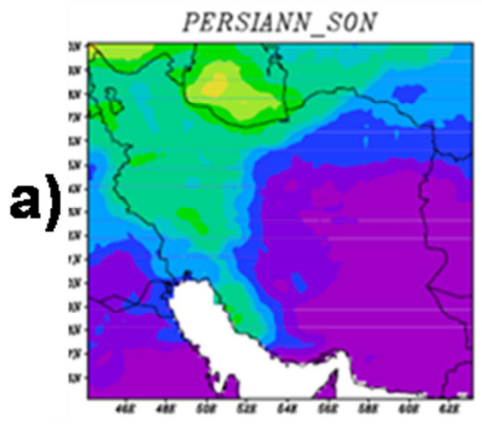

PERSIANN_DJF

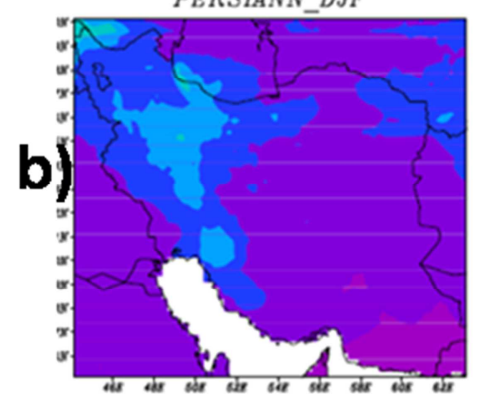

PERSIANN_MAM
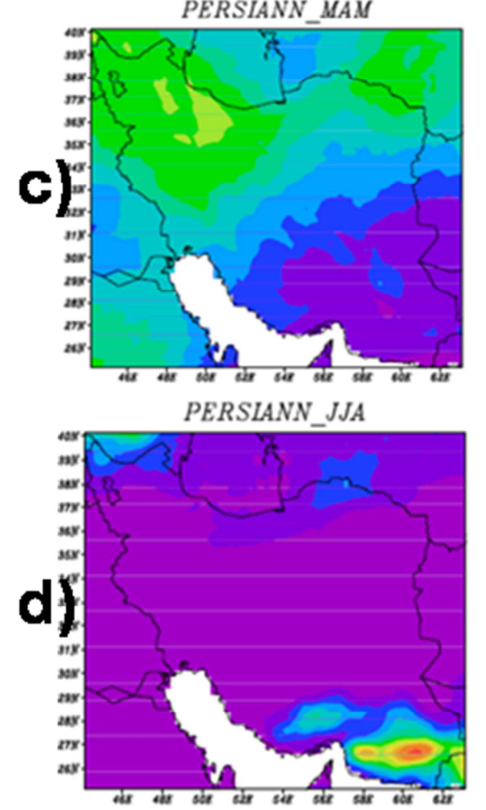
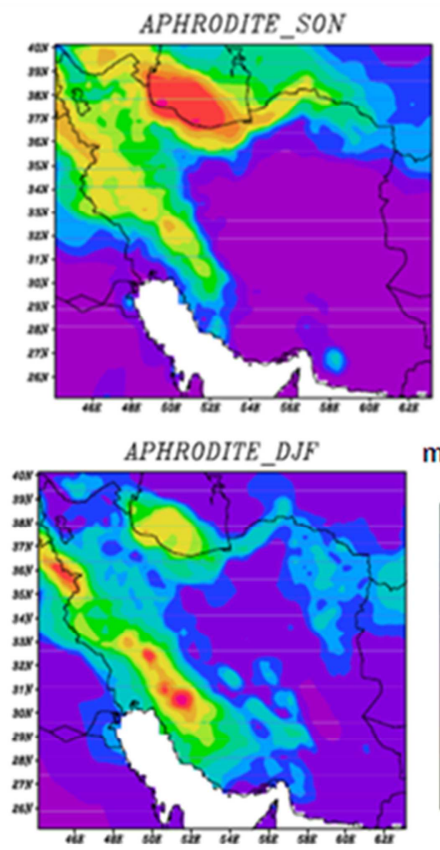

APHRODITE_MAM

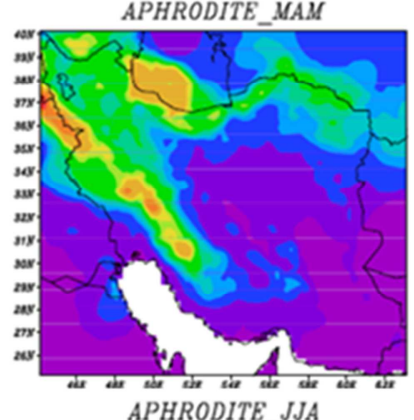

APHRODITE JJA

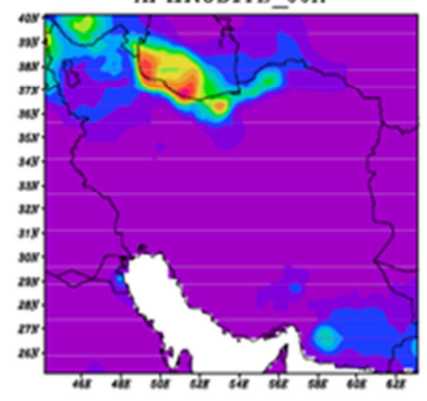

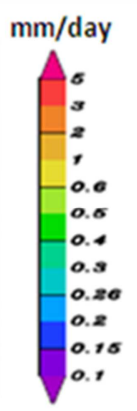

$\mathrm{mm} / \mathrm{day}$

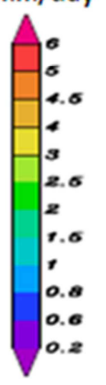

$\mathrm{mm} /$ day

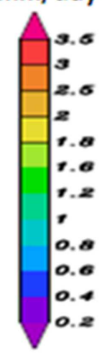

$\mathrm{mm} /$ day

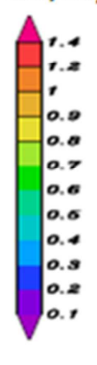

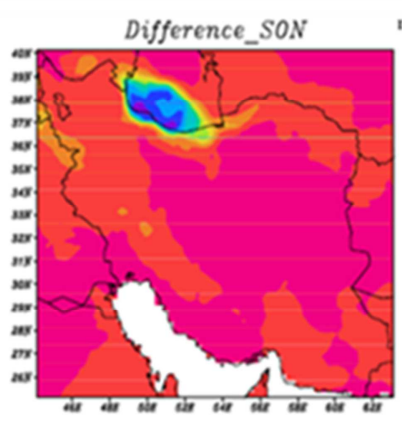
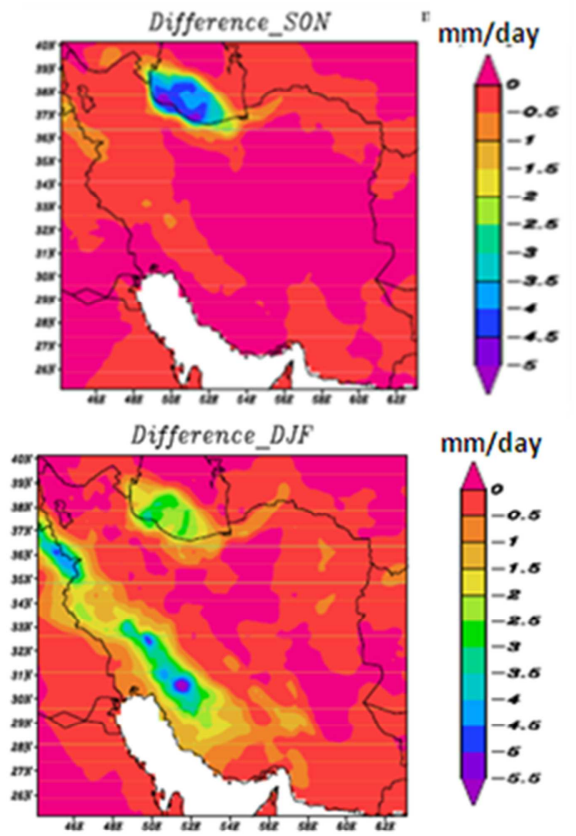

$\mathrm{mm} /$ day

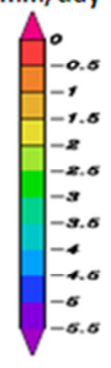

Difference_MAM

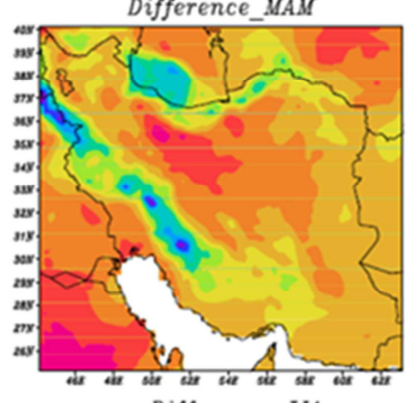

$\mathrm{mm} /$ day

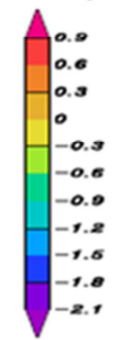

$\mathrm{mm} /$ day
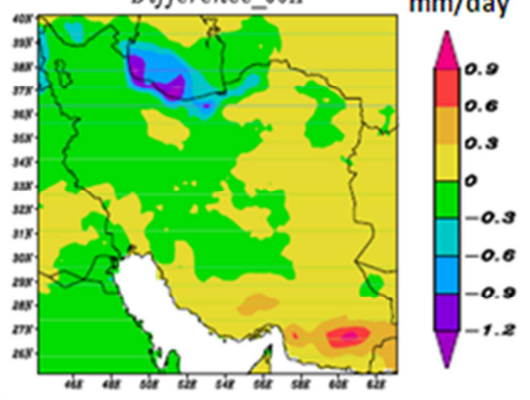

Figure 5. Comparison of mean seasonal precipitation by APHRODITE and PERSIANN for (a) winter, (b) spring, (c) autumn, and (d) summer over Iran during the period of 2001-2007. In all cases, the middle image indicates APHRODITE estimates (mm/day), the left image indicates PERSIANN estimates (mm/day), and the right image is the difference in mean seasonal precipitation between APHRODITE and PERSIANN (mm/day) (PERSIANN-APHRODITE). DJF (December, January, and February), JJA (June, July, and August), MAM (March, April, and May), and SON (September, October, and November). 


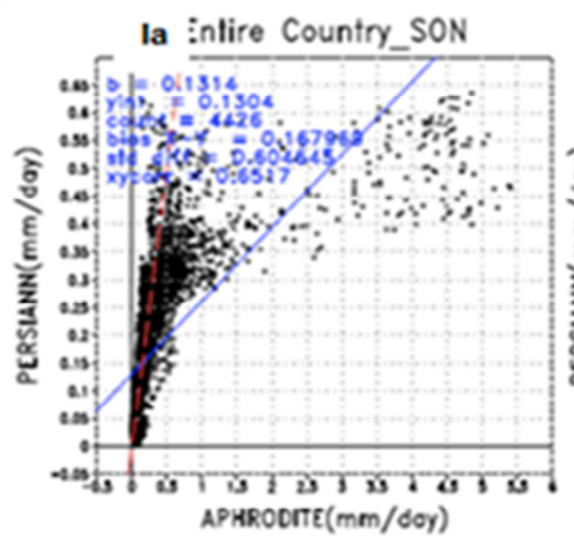

Ib Enlire Country_DJF

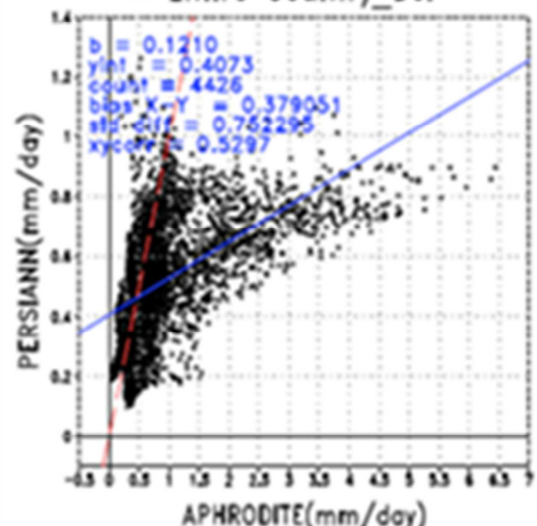

Ic Entire Country_MAM

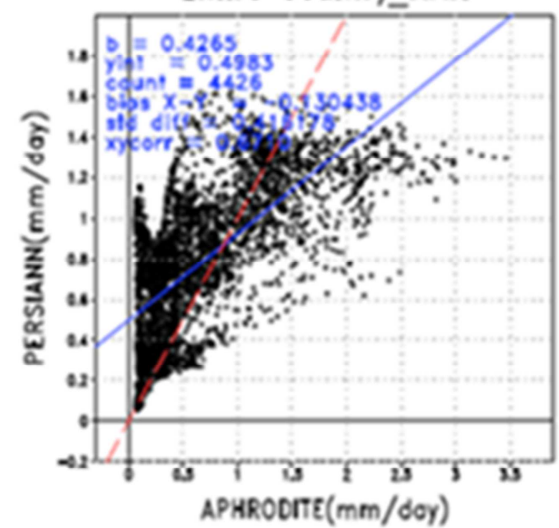

Ila Zagros Mountains_SON

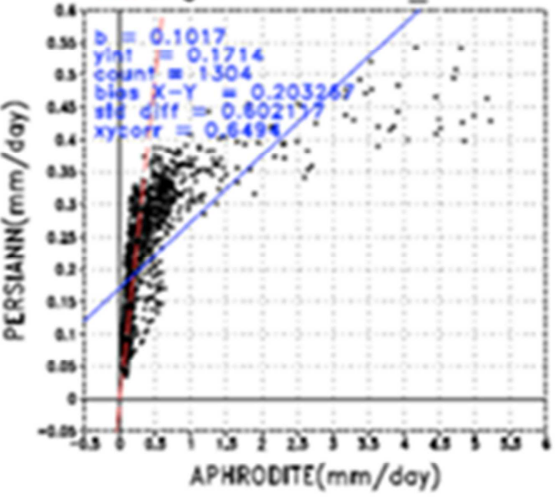

Ilb Zagros Mountains_DJF

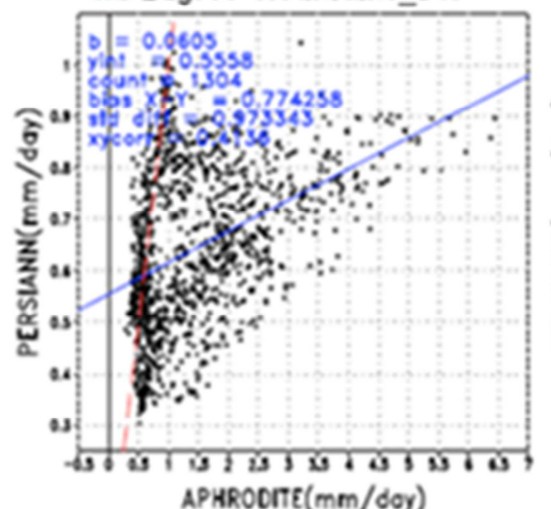

Ilc Zagros Mountains_MAN

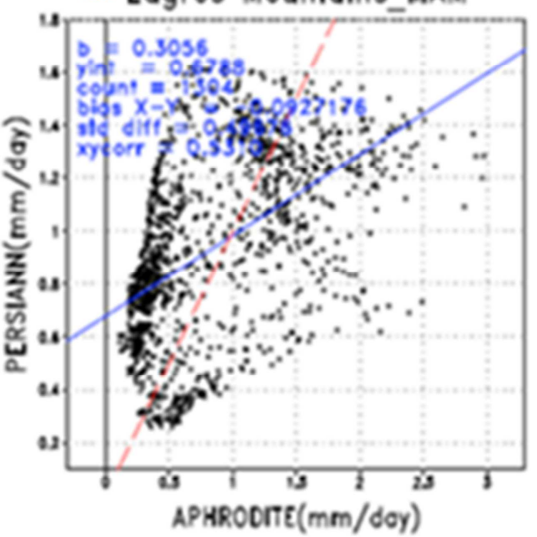

Illa Caspion See_SON

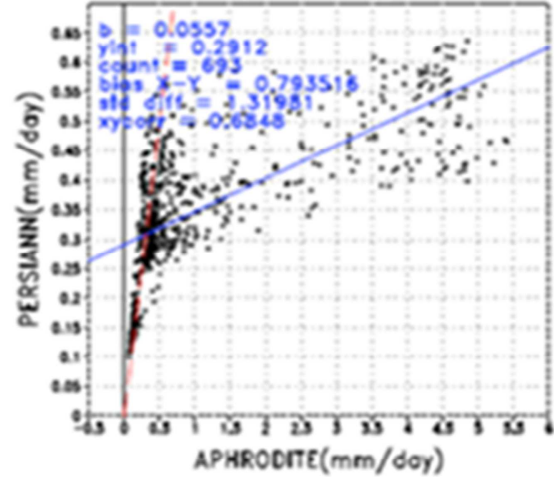

IIIb Caspion See_DJF

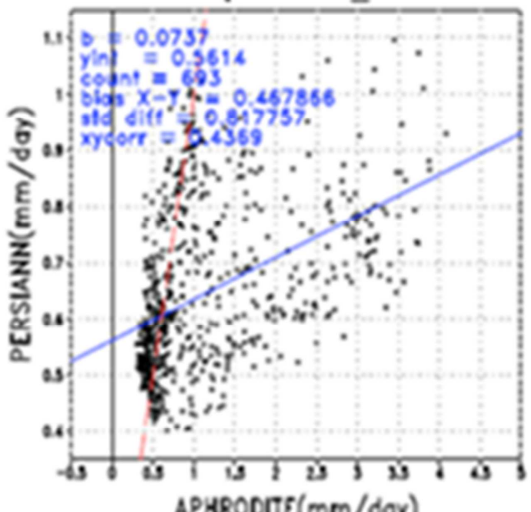

APHROORE( $\mathrm{mm} /$ doy)

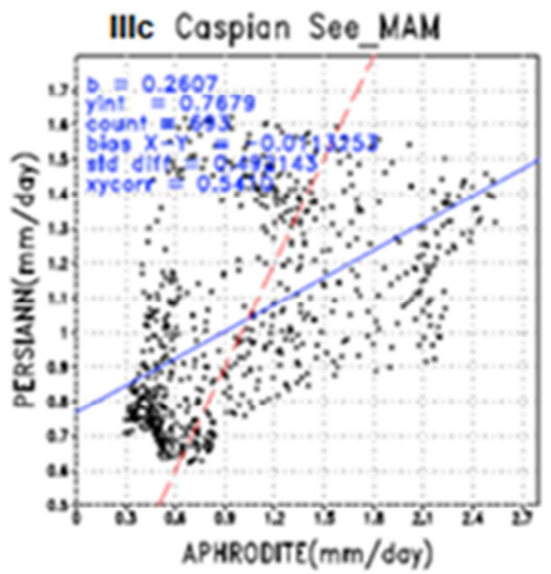

Figure 6. Scatter plots of mean seasonal rainfall for the autumn season (Ia-IIIa), the winter season (Ib-IIIb), and the spring season(Ic-IIIc), from PERSIANN versus APHRODITE for each grid cell. In all cases, I is the entire country, II is the Zagros Mountains region, and III is the Caspian Sea region.

Table 1. Statistical parameters of linear regression and spatial correlation coefficient of scatter plots of annual average of rainfall from APHRODITE versus PERSIANN for each grid cell in three regions: the entire country (Region 1), the Caspian Sea (Region 2), and the Zagros Mountains (Region 3).

\begin{tabular}{lllllll}
\hline $\begin{array}{l}\text { Selected } \\
\text { Regions }\end{array}$ & $\begin{array}{l}\text { Slope } \\
\text { Parameter }\end{array}$ & $\begin{array}{l}\text { Intercept } \\
\text { Parameter }\end{array}$ & $\begin{array}{l}\text { Samples } \\
\text { Number }\end{array}$ & $\begin{array}{l}\text { Bias (mm/day) } \\
\text { (PERSIANN- APHRODITE) }\end{array}$ & $\begin{array}{l}\text { Standard Deviation } \\
\text { (mm/day) }\end{array}$ & $\begin{array}{l}\text { Spatial Correlation } \\
\text { Coefficient }\end{array}$ \\
\hline Region 1 & 0.16 & 0.27 & 4426 & -0.14 & 0.46 & 0.62 \\
Region 2 & 0.07 & 0.42 & 1304 & -0.45 & 0.78 & 0.62 \\
Region 3 & 0.10 & 0.33 & 693 & -0.30 & 0.51 & 0.47 \\
\hline
\end{tabular}

Table 2 shows root mean square error (RMSE) between PERSIANN and APHRODITE annual precipitation data for all grid points over the study area for each year from 2001 to
2007. The range of this value is 0.41 to $0.52(\mathrm{~mm} /$ day $)$. RMSE has varied from 0.52 in 2004 to lower values in following years. 
Table 2. RMSE between PERSIANN and APHRODITE annual precipitation data in all grid points over the study area for each year from 2001 to 2007.

\begin{tabular}{llllllll}
\hline Year & $\mathbf{2 0 0 1}$ & $\mathbf{2 0 0 2}$ & $\mathbf{2 0 0 3}$ & $\mathbf{2 0 0 4}$ & $\mathbf{2 0 0 5}$ & $\mathbf{2 0 0 6}$ & $\mathbf{2 0 0 7}$ \\
\hline $\begin{array}{l}\text { RMSE } \\
\text { (mm/day) }\end{array}$ & 0.46 & 0.51 & 0.51 & 0.52 & 0.51 & 0.46 & 0.41 \\
\hline
\end{tabular}

\subsection{Mean Seasonal Precipitation}

\subsubsection{Visual Comparison of Spatial Distribution of Precipitation}

Iran receives its highest amount of precipitation, often originating from stratiform clouds, during the winter (December, January, and February [DJF]), but the convective clouds mostly cause precipitation over the country in the late winter and early spring. Figure 5 shows comparison of mean winter precipitation between APHRODITE $\left(0.25^{\circ} \times 0.25^{\circ}\right)$ and PERSIANN $\left(0.25^{\circ} \times 0.25^{\circ}\right)$ from 2001 through 2007. PERSIANN significantly underestimates rainfall in winter, with a maximum underestimation of approximately 5.5 $\mathrm{mm} /$ day, occurring in the southwest of the country along the Zagros Mountains. PERSIANN has detected the mean winter precipitation up to $1.5 \mathrm{~mm} /$ day, whereas this amount is 6 $\mathrm{mm} /$ day for APHRODITE data. PERSIANN has a different performance in spring (March, April, and May [MAM]), and it is successful in detecting rain with fewer positive bias values (Table 3).It has a tendency to overestimate low amounts of rainfall in the central part of Iran by approximately $0.3-0.9 \mathrm{~mm} /$ day, and underestimate high amounts of rainfall along the Caspian Sea and the Zagros Mountains by a maximum of $1.8 \mathrm{~mm} /$ day (Figure 5 ).

During autumn (September, October, and November [SON]), when heavy rainfall is associated with convective clouds over the Zagros Mountain chain (northwest through southwest) and the Alborz Mountain chain (northwest toward northeast, including southern coastal areas of the Caspian Sea), PERSIANN has high accordance with APHRODITE ground-based data to detect rainfall pattern. However, PERSIANN strongly underestimates rainfall amounts over the southern Caspian Sea, by a maximum of $\sim 5 \mathrm{~mm} /$ day in autumn (Figure5).

Moreover, during summer (June, July, and August [JJA]), when the Caspian Sea region is predominated by warm clouds characterized mostly by low-level stratiform clouds and high rainfall occurs over the Caspian Sea region, PERSIANN underestimates the rainfall values by up to 1.2 $\mathrm{mm}$ /day. On the other hand, PERSIANN has detected a rainy region affected by a monsoon precipitation regime in the southeast of the country and overestimates mean summer precipitation by approximately $0.9 \mathrm{~mm} /$ day (Figure5), which might be related to the lack of sufficient number of raingauges in that region.

\subsubsection{Statistical Analysis}

Figures 6-Ia to 6-Ic show the scatter plots for comparing mean seasonal precipitation in APHRODITE and PERSIANN (2001-2007) for autumn (a), winter (b) and spring (c) over three selected regions based on the gridded data sets: the entire country (I), the Zagros Mountain (II), and the Caspian Sea costal area (III). Statistical parameters derived in linear regression and SCC between mean seasonal rainfall of APHRODITE and PERSIANN are presented in Table 3. SCCs are $0.65,0.64$, and 0.68 in autumn; $0.52,0.43$, and 0.41 in winter; and $0.68,0.54$ and 0.53 in spring, for regions(I), (II), and (III), respectively.

In autumn (SON), PERSIANN provides generally good estimations for the spatial pattern of rainfall but has a tendency to underestimate high-rainfall values and overestimate low-rainfall values (Figure 6).This finding indicates a good agreement between PERSIANN and APHRODITE in the observed rainfall pattern according to visual comparison.

The PERSIANN algorithm performs well for mean seasonal precipitation in winter, with a difference value lower than $1 \mathrm{~mm} /$ day, but it significantly underestimates the high values of rainfall, with a maximum difference of approximately $5.5 \mathrm{~mm} /$ day.

A negative bias occurs in autumn and spring and a positive bias occurs in winter over the three selected regions, indicating underestimation of mean rainfalls of autumn and spring and overestimation of the mean winter rainfall by PERSIANN (Table 3).

Table 3. Statistical parameters derived by use of linear regression and spatial correlation coefficient between mean seasonal rainfall from APHRODITE and PERSIANN for autumn (Ia-IIIa), winter (Ib-IIb), and spring (Ic-IIIc).

\begin{tabular}{|c|c|c|c|c|c|}
\hline $\begin{array}{l}\text { Spatial Correlation } \\
\text { Coefficient }\end{array}$ & $\begin{array}{l}\text { Standrd Deviation } \\
(\mathrm{mm} / \mathrm{day})\end{array}$ & $\begin{array}{l}\text { Bias(mm/day) } \\
\text { (PERSIANN-APHRODITE) }\end{array}$ & Intercept Parameter & Slope Parameter & Figures \\
\hline 0.52 & 0.75 & -0.37 & 0.40 & 0.12 & Ia \\
\hline 0.41 & 0.97 & -0.77 & 0.55 & 0.06 & IIa \\
\hline 0.43 & 0.81 & -0.46 & 0.56 & 0.07 & IIIa \\
\hline 0.68 & 0.41 & 0.22 & 0.55 & 0.48 & $\mathrm{Ib}$ \\
\hline 0.53 & 0.49 & 0.09 & 0.67 & 0.30 & $\mathrm{IIb}$ \\
\hline 0.54 & 0.49 & 0.01 & 0.76 & 0.26 & $\mathrm{IIIb}$ \\
\hline 0.64 & 0.60 & -0.20 & 0.17 & 0.10 & IIc \\
\hline 0.68 & 1.13 & -0.79 & 0.29 & 0.05 & IIIc \\
\hline
\end{tabular}

\subsection{Inter-Annual Comparison}

Figure 8 shows a comparison between a time series of monthly areal average of precipitation (MAAP) over Iran $\left(25^{\circ}-40^{\circ} \mathrm{N}, 44^{\circ}-63^{\circ} \mathrm{E}\right)$ in APHRODITE and PERSIANN from 2001 through 2007. The fluctuations in variation of MAAP in APHRODITE and PERSIANN accord well with each other. Maximum MAAP occurs in winter (except for the 
year 2002) for APHRODITE and in spring for PERSIANN, and minimum rainfall occurs each summer in both APHRODITE and PERSIANN (Figure7). Comparison of areal rainfall average shows that PERSIANN underestimated rainfall in the months of January to March in winter and overestimated rainfall in April and May from 2001 through 2007, compared with APHRODITEPERSIANN strongly overestimated rainfall in April and May of 2007.This outcome might be related to the improvement in the PERSIANN algorithm. However, further research and investigation should be done to verify this possibility. The maximum of areal average is $2.7 \mathrm{~mm}$ /day for the PERSIANN estimation for April 2007,which is close to the observed value of $2.5 \mathrm{~mm}$ /day for APHRODITE by gridded precipitation datasets $\left(0.25^{\circ} \times 0.25^{\circ}\right.$ latitude/longitude $)$, based on rain gauges (Iran Synoptic gauges Version 0902 [IS0902])in Javanmard et al.[2010] ${ }^{5}$ ) and is $1.6-1.8 \mathrm{~mm} /$ day in December 2004 for APHRODITE (Figure 7).Furthermore, the Pearson correlation coefficient $(r)$ and the coefficient of determination $\left(\mathrm{R}^{2}\right)$ between the monthly average areal precipitation data series of PERSIANN and APHRODITE for all months during 2001-2007 are approximately 0.58 and 0.33 , respectively, which confirm the existence of partially agreement between them.

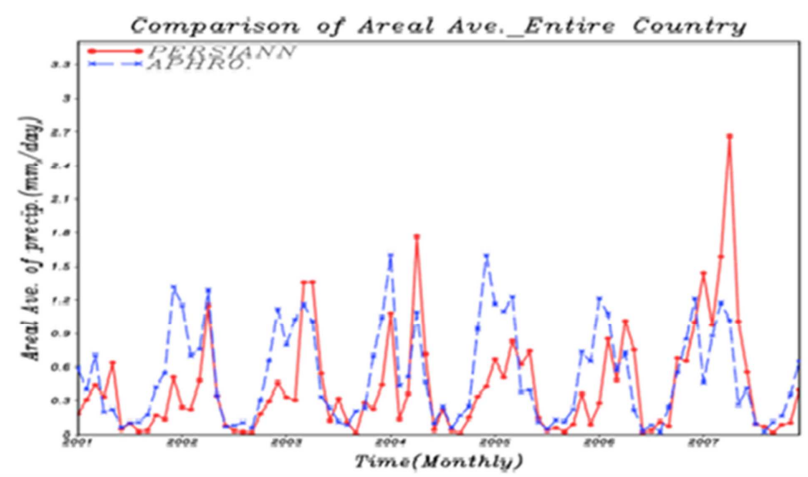

Figure 7. Monthly average areal precipitation by APHRODITE (blue dashed line) and PERSIANN (red solid line) over Iran from January2001 to December2007.
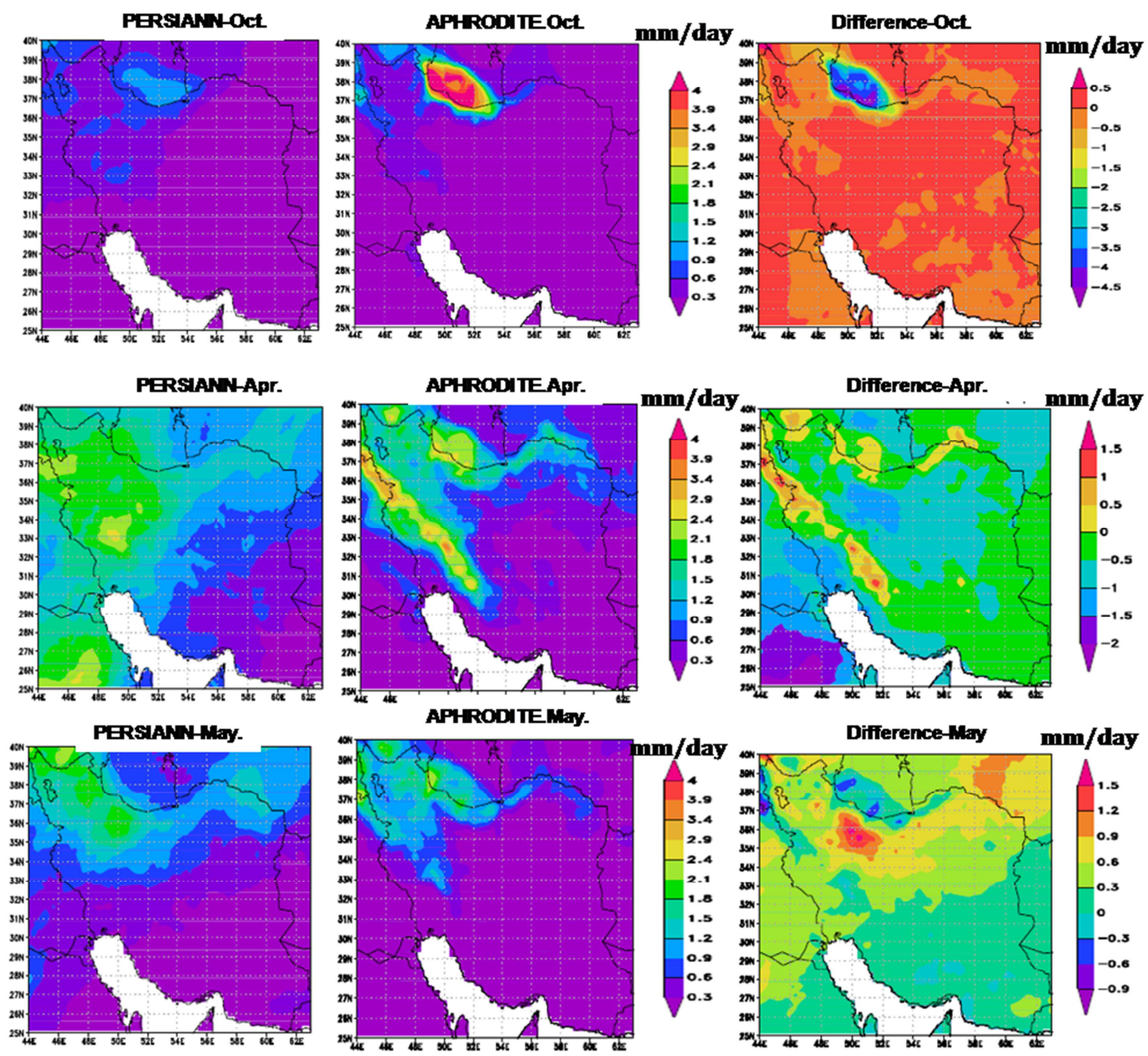

Figure 8. Spatial patterns of monthly areal average and monthly difference of precipitation over Iran in APHRODITE and PERSIANN from 2001 to 2007, for October (top), April (middle), and May (bottom). 
Because the rainy period is from November to May for most parts of the country, in this section, the performance of PERSIANN in these months has been evaluated. Tables4 and5 give statistical parameters derived from linear regression and the SCCs between mean monthly rainfall in both the Zagros Mountains and the Caspian Sea region during the time period of 2001-2007 from the data sets of APHRODITE and PERSIANN. In the Caspian Sea region, PERSIANN has a good performance, with continuous high
SCCs with ground-based data from October to December. However, SCCs decrease during January to March in the two regions, indicating low accordance between PERSIANN estimates and APHRODITE data, and again, the SCC values increase during April and May in both the regions, as this finding illustrates high ability of PERSIANN to detect rain occurrence in these two months. The minimum value of SCC is 0.2 for November in the Zagros Mountains (Table 5).

Table 4. Statistical parameters derived in scatter plots from PERSIANN versus APHRODITE for mean monthly rainfall during 2001-2007over the Caspian Sea region $(N=693)$.

\begin{tabular}{|c|c|c|c|c|c|}
\hline $\begin{array}{l}\text { Spatial Correlation } \\
\text { Coefficient }\end{array}$ & $\begin{array}{l}\text { Standard Deviation } \\
(\mathrm{mm} / \text { day })\end{array}$ & $\begin{array}{l}\text { Bias (mm/day) } \\
\text { (PERSIANN-APHRO.) }\end{array}$ & Slope Parameter & Intercept Parameter & Month \\
\hline 0.70 & 1.23 & -0.54 & 0.45 & 0.11 & October \\
\hline 0.52 & 1.71 & -1.29 & 0.34 & 0.03 & November \\
\hline 0.67 & 1.27 & -0.89 & 0.50 & 0.05 & December \\
\hline 0.41 & 0.55 & -0.14 & 0.66 & 0.14 & January \\
\hline 0.36 & 0.59 & -0.36 & 0.49 & 0.09 & February \\
\hline 0.44 & 0.65 & -0.27 & 0.78 & 0.12 & March \\
\hline 0.61 & 0.43 & 0.26 & 0.67 & 0.48 & May \\
\hline
\end{tabular}

Table 5. Statistical parameters derived in scatter plots from PERSIANN versus APHRODITE for mean monthly rainfall during 2001-2007over the Zagros Mountains $(N=1304)$.

\begin{tabular}{|c|c|c|c|c|c|}
\hline $\begin{array}{l}\text { Spatial Correlation } \\
\text { Coefficient }\end{array}$ & $\begin{array}{l}\text { Standard Deviation } \\
(\mathrm{mm} / \text { day })\end{array}$ & $\begin{array}{l}\text { Bias(mm/day) } \\
\text { (PERSIANN-APHRO.) }\end{array}$ & Slope Parameter & Intercept Parameter & Month \\
\hline 0.63 & 0.57 & -0.01 & 0.23 & 0.22 & October \\
\hline 0.20 & 0.91 & -0.42 & 0.38 & 0.03 & November \\
\hline 0.59 & 1.19 & -1.11 & 0.45 & 0.07 & December \\
\hline 0.22 & 0.55 & -0.14 & 0.66 & 0.14 & January \\
\hline 0.34 & 0.59 & -0.36 & 0.49 & 0.09 & February \\
\hline 0.29 & 0.65 & -0.27 & 0.78 & 0.12 & March \\
\hline 0.79 & 0.43 & 0.26 & 0.67 & 0.48 & May \\
\hline
\end{tabular}

\section{Discussion and Conclusion}

In this investigation, the performance and capabilities of the PERSIANN algorithm (at both monthly and seasonal timescales) have been validated with gridded precipitation V1003R1 output data from the APHRODITE project (APHRO_V1003R1). The most important results about the performance of the PERSIANN algorithm are as follows:

1. The existence of different seasonal precipitation patterns over the country has been found.

2. PERSIANN significantly underestimates high rainfall values, especially in the winter, the rainiest season, by a maximum difference of $5.5 \mathrm{~mm} /$ day.

3. The algorithm successfully detects rainfall patterns in autumn, except for November in the Zagros Mountains, but underestimates rainfall values, especially along the Caspian Sea.

4. Rainfall patterns derived from PERSIANN and APHRODITE are very similar throughout most of the country in the spring. However, spatial evaluation shows that PERSIANN underestimates rainfall over the southern part of the Caspian Sea region (toward the northeast of Iran) and the Zagros Mountains, but it overestimates rainfall amounts over the rest of the country (mostly the central parts).

5. Comparison of average areal rainfall between PERSIANN and APHRODITE over the country shows that PERSIANN overestimates rainfall, mostly in the spring, and the maximum overestimation is approximately $1.7 \mathrm{~mm} /$ day, in April 2007. On the other hand, it underestimates rainfall in the winter, and the maximum underestimation is approximately1.1 $\mathrm{mm} /$ day, in December 2004. The reason for the underestimation in the winter might be related to the lack of good recognition between snow and rain.

Gridded observational data of both APHRODITE and PERSIANN show that spatial distribution of mean annual and seasonal precipitation over Iran has two main patterns: along the Caspian Sea and in the Zagros Mountains. This finding is in accordance with Javanmard et al. (2010) ${ }^{5}$, who showed the same result using TRMM3B42 rainfall estimates compared with IS0902 rain-gauge--based data.

The scatter plot between mean annual precipitation estimated by PERSIANN and mean annual gridded precipitation from synoptic network data duringthe 7- year period from 2001 to 2007 was derived for the three study regions (the entire country, the Caspian Sea, and the Zagros 
Mountains) and showed spatial correlation coefficients of $0.62,0.62$, and 0.47 , respectively. PERSIANN underestimates the amount of mean annual rainfall values along the Caspian Sea and the Zagros Mountains by approximately $2.7 \mathrm{~mm} /$ day, and the range of mean rainfall values in APHRODITE data is 1.6-1.8 mm/day.

PERSIANN recognizes the existence of different seasonal precipitation regimes over the country in three rainy seasons: spring, autumn, and winter. However, PERSIANN significantly underestimates the high rainfall amounts in spring, autumn, and winter. Results show that spatial distribution of mean annual and seasonal precipitations over Iran has two main patterns: over the region along the Caspian Sea (northern parts of Iran) and in the Zagros Mountains (from northwest to southeast). Comparison of spatial distribution of gridded precipitation data and PERSIANN showed a good accordance in rainfall pattern during autumn, although it underestimates the amount of precipitation. PERSIANN overestimated rainfall in April and May over both regions.

Although PERSIANN underestimates rainfall over most regions of the country and during most months of the year, the significance of this validation of the PERSIANN data is that it is successful in precipitation estimation over the regions where rain-gauges are distributed sparsely (e.g., in the southeast of the country) during the monsoon season. Therefore, the PERSIANN algorithm can be helpful for water resource management in such areas and especially during the spring (April and May) season. Further research should be performed to verify the accuracy of PERSIANN over the country, and the PERSIANN data series should be compared with other satellite-based rainfall outputs, such as the TRMM data series, which has a better algorithm calibrated with ground-based precipitation data.

\section{References}

[1] Ebert, N. Kerle, and A. Stein, 2007: Remote sensing based assessment of social vulnerability, the space policy institute, George Washington University.

[2] Jensen, N. E. and L. Pedersen, 2005: Spatial variability of rainfall: Variations within a single radar pixel, Atmos.Res.,77,269-277

[3] Hong G., P. Yang, B.C. Gao, B. A. Baum, Y.X. Hu, M.D. King, and S. Platnicks, 2007: High cloud properties from three years of MODIS Terra and Aqua collection- 4 data over the tropics, J. Appl. Meteor. Climatol., 46, 1840-1856.

[4] Sorooshian S, K-L. Hsu, B. Imam, Y. Hong, 2006: Global precipitation estimation from satellite imagery using artificial neural networks. Chapter 2in Hydrological Modeling in Arid and Semi-arid Areas. UNESCO.

[5] Javanmard S., A. Yatagai, M. I. Nodzu, J. Bodagh Jamali, and H. Kawamoto, 2010: Comparing high-resolution gridded precipitation data with satellite rainfall estimates of TRMM_3B42 over Iran, Adv. Geosci., 25, 119-125

[6] Kamali Gh. A., A. Asgari, and K. Noohi, 2009: Applied Meteorology, Atmospheric Science and Meteorological
Research Center (ASMERC), Tehran, Iran, pp. 271 (in Persian language).

[7] Hsu, K., X. Gao, S. Sorooshian, and H.V. Gupta, 1997: Precipitation estimation from remotely sensed information using artificial neural networks, J. Appl. Meteor., 36, 11761190 .

[8] Hsu, K., H. V. Gupta, X. Gao, and S. Sorooshian, 1999: Estimation of physical variables from multi-channel remotely sensed imagery using a neural network: Application to rainfall estimation, Water Resources Res., 35(5), 1605-1618.

[9] Ferraro, R. R., and G. F. Marks, 1995: The development of $\mathrm{SSM} / \mathrm{I}$ rain-rate retrieval algorithms using ground-based radar measurements, J. Atmos. Oceanic Technol., 12, 755-770.

[10] Janowiak, J. E., R. J. Joyce, and Y. Yarosh, 2000: A real-time global half-hourly pixel resolution infrared dataset and its applications, Bull. Amer. Meteor. Soc., 82,205-217.

[11] Sorooshian, S., K. Hsu, X. Gao, H.V. Gupta, B. Imam, and D. Braithwaite, 2000: Evaluation of PERSIANN system satellitebased estimates of tropical rainfall, Bull. Amer. Meteor. Soc., $81,2035-2046$.

[12] Weng, F., L. Zhao, R. Ferraro, G. Poe, X. Li, and N. Grody, 2003: Advanced microwave sounding unit cloud and precipitation algorithms, Radio Sci.,38, 8086-8096.

[13] Sorooshian S., Lawford R., Try P., Rossow W., Roads J., Polcher J., Sommeria G., and Schiffer R., 2005: Water and energy cycles: investigating the links. WMO Bull.54, 58-64

[14] Gruber A., and V. Levizzani, 2008: Assessment of global precipitation products, WCRP Report, 128, WMO/TD-No. 1430.

[15] Yatagai, A., O. Arakawa, K. Kamiguchi, H. Kawamoto, M. I. Nodzu, and A. Hamada, 2009: A 44-year daily gridded precipitation dataset for Asia based on a dense network of rain gauges, SOLA, 5, 137-140, DOI:10.2151.

[16] Turk, F. J., P. Arkin, E. E. Ebert, and M. R. P. Sapiano, 2008: Evaluating high-resolution precipitation products, Bull. Amer. Meteor. Soc., 89, 1911-1916.

[17] Ebert, E. E., and M. J. Manton, 1998: Performance of satellite rainfall estimation algorithms during TOGA COARE, J. Atmos. Sci., 55, 1537-1557.

[18] Chen, M., W. Shi, P. Xie, V. B. S. Silva, V. E. Kousky, R. Wayne Higgins, and J. E. Janowiak, 2008: Assessing objective techniques for gauge-based analyses of global daily precipitation, J. Geophys. Res., 113, D04110, doi: 10.1029/2007 JD009132.

[19] Xie, P., and P. A. Arkin, 1997: Global precipitation: A17-year monthly analysis based on gauge observations, satellite estimates, and numerical model outputs. Bull. Amer. Meteor. Soc., 78, 2539-2558.

[20] Adler, R. F., G. J. Huffman, A. Chang, R. Ferraro, P. Xie, J. Janowiak, B. Rudolf, U. Schneider, S. Curtis, D. Bolvin, A. Gruber, J. Susskind, P. Arkin, and E. Nelkin, 2003: The Version 2 Global Precipitation Climatology Project (GPCP) monthly precipitation analysis (1979-present), J. Hydrometeor., 4, 1147-1167.

[21] Yatagai, A., P. Xie, and A. Kitoh, 2005: Utilization of a new gauge-based daily precipitation dataset over monsoon Asia for validation of the daily precipitation climatology simulated by the MRI/JMA 20-km-mesh AGCM. SOLA, 1, 193-196, doi: 10.2151 . 
[22] Huffman, G. J., R. F. Adler, M. Morrissey, D. Bolvin, S. Curtis, R. Joyce, B. Mc Gavock, and J. Susskind, 2001: Global precipitation at one-degree daily resolution from multisatellite observations, J. Hydrometeor., 2, 36-50.

[23] Hijmans, R. J., S. E. Cameron, J. L. Parra, P. G. Jones, and A.
Jarvis, 2005: Very high resolution interpolated climate surfaces for global land areas, Int. J. Climatol., 25, 1965-1978.

[24] Shepard, D., 1968: A two-dimensional interpolation function for irregularly spaced data, Proc. 23 ACM Nat'l Conf., Princeton, N.J., Barandon/Systems Press, 517-524.

\section{Biography}

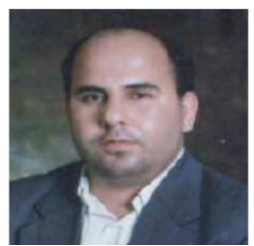

Dr. Javad BodaghJamali is a faculty member and assistant professor at the University of Environment, Karaj, Iran and he currently heads the Atmospheric Science and Meteorological Research Center (ASMERC), Tehran, Iran. He acquired his Ph.D. degree in Physics from the Faculty of Science, Kyushu University, Japan in 1998. His research interests are natural disaster risk management, drought monitoring and early warning, climate change and global warming, and experimental study of magnetism of organic free radicals. 